Cadernos de Filosofia Alemã 4, PP. 31-41, 1998

\title{
Exposição e gênio na Crítica do Juízo
}

\author{
Luís F. S. Nascimento*
}

Resumo: Trata-se de investigar a relação entre as noções de Darstellung e de gênio tal como elas aparecem na Crítica do Juízo de Kant.

Palavras-chave: exposição - gênio - bela-arte

Para os Márcios

"Um gênio para as belas artes implica não somente o poder de invenção ou desígnio, mas da mesma maneira a capacidade de expressar seus desígnios em materiais adequados. Sem isso, seria não apenas imperfeito, mas permaneceria sempre latente, encoberto e inútil."

Alexander Gerard, An essay on taste (1759)**

É possível, para Kant, considerar alguém como gênio sem a exposição (Darstellung) de sua obra? Para ilustrar essa questão, na tentativa de torná-la mais clara, tomamos a liberdade de nos utilizar do conto Cantiga de esponsais de Machado de Assis. Esse conto narra a história de Romão Pires ou simplesmente mestre Romão, tal como o exercício de sua profissão o tornou conhecido. Músico renomado, regente de sucesso, mestre Romão parece não ter mo-

\footnotetext{
* Mestrando no Departamento de Filosofia da FFLCH/USP e bolsista FAPESP.

** “A genius for fine arts implies, not only the power of invention or desing, but likewise a capacity to express its designs in art materials. Without this, it would not only be imperfect, but would for ever lie latent, undiscovered, and useless". Em: An Essay on Taste. Nova York, Schular's Facsimiles and Repreints, 19778.
} 
tivos para a infelicidade. Enquanto rege uma missa, embriagado pelo som que acompanha sua batuta, ele não tem do que se queixar. Diante da orquestra, mestre Romão é pura alegria: é como se a missa que está regendo fosse dele. Mas, quando tudo acaba, na ocasião em que tem de voltar para casa, mestre Romão é obrigado a enfrentar uma tristeza que o persegue por toda a vida. Nesses momentos, em que se encontra sozinho, vem à tona um sentimento desconhecido por todos aqueles que o cercam. As pessoas não podem entender o motivo de tamanha angústia e casmurrice, que se refletem nos móveis e na pouca luz de sua casa. A razão de sua tristeza não é outra senão o fato de não ser capaz de compor. Não que lhe falte estudo e vontade para tanto, mas, por algum motivo desconhecido, mestre Romão não possui a maneira adequada de exteriorizar seus sentimentos. Chega, por vezes, a sentir um lampejo, um frenesi que lhe toma todo o corpo, mas que não vai além disso. Entre as pontas dos dedos de mestre Romão e as teclas de seu cravo existe um enorme abismo. Abismo que, nas palavras de Machado, é assim expresso:

“Ah! se mestre Romão podesse seria um grande compositor. Parece que há duas sortes de vocação, as que tem língua e as que a não tem. As primeiras realizam-se; as últimas representam uma luta constante e estéril entre o impulso interior e a ausência de um modo de comunicação com os homens. Romão era destas. Tinha a vocação íntima da música; trazia dentro de si muitas óperas e missas, um mundo de harmonias novas e originais que não alcançava exprimir e pôr no papel. Esta era a causa única da tristeza de mestre Romão. Naturalmente o vulgo não atinava com ela; uns diziam isto, outros aquilo: doença, falta de dinheiro, algum desgosto antigo; mas a verdade é esta - a causa da melancolia de mestre Romão era não poder compor, não possuir $o$ meio de traduzir o que sentia. Não é que não rabiscasse muito papel e não interrogasse o cravo, durante horas; mas tudo lhe saía informe, sem idéa nem harmonia. Nos últimos tempos tinha até vergonha da vizinhança, e não tentava mais nada.

E, entretanto, se pudesse, acabaria ao menos uma certa peça, um canto esponsalício, começado três dias depois de casado, em 1779. A mulher, que ainda tinha então vinte e um anos, e morreu com vinte e três, não era muito bonita, nem pouco, mas extremamente simpática, e amava-o tanto como ele a ela. Três dias depois de casado, mestre Romão sentiu em si alguma coisa parecida com inspiração. Ideou então o canto esponsalício, e quis compô-lo; 
mas a inspiração não poude sair. Como um pássaro que acaba de ser preso, e forceja por transpor as paredes da gaiola, abaixo, acima, impaciente, aterrado, assim batia a inspiração do nosso músico, encerrada nele sem poder sair, sem achar uma porta, nada. Algumas notas chegaram a ligar-se; ele escreveu-as; obra de uma folha de papel, não mais. Teimou no dia seguinte, dez dias depois, vinte vezes durante o tempo de casado. Quando a mulher morreu, ele releu essas primeiras notas conjugais, e ficou ainda mais triste, por não ter podido fixar no papel a sensação de felicidade extinta" (Assis 1, pp. 84-85, grifos nossos) ${ }^{1}$.

Mestre Romão começa o que seria sua obra-prima, o canto esponsalício, em 1779, três dias depois de seu casamento. Passam-se dois anos, sua mulher morre, passam-se mais tantos anos, o viúvo mestre Romão já está na casa dos sessenta anos e ainda não terminou seu canto esponsalício. Se voltarmos agora à nossa questão inicial, então podemos perguntar: será que mestre Romão, como vocação que não encontra modo de comunicação com os homens, pode ser considerado gênio dentro daquilo que Kant designou como tal?

A Crítica do Juízo apresenta a noção de bela-arte como sendo obra de gênio. Se tomarmos o parágrafo 43 da Crítica do Juízo como parâmetro para a compreensão da bela-arte, ela nos aparecerá como um termo extremamente contraditório. O parágrafo 43 começa por distinguir arte de natureza, para depois distinguir arte de ciência e, por fim, diferenciar arte do que Kant chama artesanato.

Kant parece estar construindo, a partir das distinções do parágrafo 43, uma concepção de arte que se esclarecerá no parágrafo seguinte. O parágrafo 44 da Crítica do Juízo, que traz por título Da arte em geral, inicia-se da seguinte maneira: "Não há uma ciência do belo, mas somente uma crítica, nem bela-ciência, mas somente bela-arte" (Kant 2, p. 244).

Surge assim o conceito de bela-arte e a contradição encerrada no mesmo conceito, pois, tal como nos mostra o parágrafo 43 , arte difere de natureza e, como veremos, o "lugar" onde se pode apreender o belo é a natureza: “(...) o correlato do juízo de gosto que melhor indicará a sua função é o objeto do qual estou certo de que ele não é efeito de uma intenção, o produto de um criador inteligente. É apenas ali onde a causalidade seguramente não é orientada, e onde a desordem exista de direito, que torna-se possível rastrear uma racionalidade que, certamente, não será demiúrgica. (...) É por isso que a na- 
tureza é por excelência o terreno neutro no qual podemos apreender o gosto em estado puro" (Lebrun 4, pp. 516-517).

Ora, se o objeto por excelência do juízo de gosto, juízo que julga o belo, é a natureza, justamente porque nela não se pode encontrar vestígios de intencionalidade, então como entender uma arte bela, visto que o que caracteriza a arte é o fato de ela ser uma obra (intencional)? Temos aqui um problema que torna difícil a união do belo ao artístico, já que, enquanto fazer humano, a arte não pode ser natural, e o objeto belo, por outro lado, não pode ser intencional. Esse problema é o próprio paradoxo inerente ao termo bela-arte: "Bela-arte, em contrapartida, é um modo-de-representação que por si mesmo é final e, embora sem fim, no entanto propicia o cultivo dos poderes-da-mente para a comunicação social. A comunicabilidade universal de um prazer traz consigo, em seu conceito, que este não deve ser um prazer de fruição, por mera sensação, mas sim da reflexão; e assim arte estética, como bela-arte, é uma arte tal que tem por justa-medida o Juízo reflexionante e não a sensação-de-sentidos" (Kant 2, p. 245).

Essa definição de bela-arte se assemelha à de belo apresentada nos primeiros vinte e dois parágrafos da Crítica do Juízo que constituem a Analítica do belo. Assim como o belo, a bela-arte desperta o sentimento de prazer (um prazer de reflexão), é uma finalidade sem fim, e se refere ao Juízo (faculdade de julgar). Essa definição, dada pelo parágrafo 44, retoma, no fim das contas, muitos aspectos presentes na de belo. Ainda não há nada de muito novo em relação à Analítica do belo e continuamos sem entender o problema da aparição do termo belo aliado ao de arte. A definição de bela-arte do parágrafo 44 não parece dar conta do problema: a bela-arte ali apresentada surge quase como sinônimo de belo e omite o fato de esse vir acompanhado do termo arte. É como se Kant ignorasse a bela-arte como arte, vendo-a apenas como bela, deixando de lado sua parcela de fazer humano. Mas, se bela-arte também é arte, se é obra de uma inteligência humana, então esse lado não pode ser ignorado. O que é, portanto, a bela-arte?

A armação desse paradoxo aponta, por sua vez, para uma relação paradoxal entre arte e natureza já apresentada no título do parágrafo 45 da Crítica do Juízo: Bela-arte é uma arte, na medida em que, ao mesmo tempo, parece natureza. Temos enfim algo distinto da Analítica do belo e que leva em conta o fato de a bela-arte ser uma arte, a saber: o parecer natureza. Entender o que vem a ser esse parecer natureza é, a nosso ver, a chave da compreensão da bela-arte. 
Porém, se tudo que se parece com algo não é esse algo, ao mesmo tempo em que, de alguma maneira, está ligado a esse mesmo algo, então temos que reconhecer que a relação entre arte e natureza permanece paradoxal. E é justamente com esse paradoxo que Kant abre o parágrafo 45: "Em um produto da bela-arte é preciso tomar consciência de que é arte, e não natureza; mas no entanto a finalidade na forma do mesmo tem de parecer tão livre de toda coação de regras arbitrárias, como se fosse um produto da mera natureza. Sobre esse sentimento da liberdade no jogo de nossas faculdades-de-conhecimento, que contudo ao mesmo tempo tem de ser final, repousa aquele prazer, que é o único universalmente comunicável, sem contudo fundar-se sobre conceitos. A natureza era bela, se ao mesmo tempo aparecia como arte; e a arte só pode ser denominada bela se temos consciência de que ela seja arte e, contudo, ela nos apareça como natureza" (Kant 2, p. 245).

A arte é bela quando a julgamos tal como julgamos a natureza. Isso não quer dizer que deixamos de saber que é ela uma arte, ao mesmo tempo em que o fato de ser arte não impossibilita em nada o seu julgamento como natureza. Aparece aqui uma expressão bastante usual em Kant: o como se $(a l s o b)^{2}$. Julgamos a bela-arte como se ela fosse natureza e é exatamente esse como se que lhe dá o direito de ser bela. O espectador da bela-arte terá de julgá-la como se ela fosse desprovida de intencionalidade. No momento do julgamento, a belaarte não pode aparecer como uma obra, um produto de um criador: "Portanto, a finalidade no produto da bela-arte, ainda que seja intencional, não deve no entanto parecer intencional: isto é, a bela-arte tem de ser considerada como natureza, ainda que se tenha consciência dela como arte" (id., ibid., p. 246).

Sendo bela, a bela-arte desperta naquele que a contempla o sentimento de prazer e desprazer, sentimento que é, nas palavras de Kant, o único capaz de ser universalmente comunicado. É na medida em que parece natureza que a bela-arte suscita o juízo de gosto de seu espectador. É também desse mesmo ponto de vista que a bela-arte pode ser chamada vivificante. Não por ela ser viva no sentido em que se vive na natureza, mas por produzir o mesmo efeito do belo natural naquele que a aprecia, ou seja: desperta o livre jogo da imaginação e do entendimento, suscitando um prazer desinteressado ${ }^{3}$. Ainda nesse mesmo sentido, poderíamos agora entender o trecho citado acima do parágrafo 44 que expõe a impossibilidade de uma ciência da bela-arte. Ela não pode ser conhecida, pois o que a caracteriza como bela-arte é o fato de ela ser objeto de um juízo de gosto e, como sabemos, esse juízo não é um juízo de conhecimento. O juízo de gosto encontra o sentimento de prazer na mera for- 
ma do julgar, e não no conhecimento do objeto sobre o qual está julgando. Nesse sentido, o objeto do juízo de gosto permanece indeterminado - não porque ele seja algo nulo, mas pela simples razão de que para esse tipo de juízo não importa o conhecimento de seu objeto. O objeto do juízo de gosto existe enquanto põe em movimento (desperta) o livre jogo entre imaginação e entendimento, mas não como objeto de um juízo de conhecimento. E é como objeto do juízo de gosto que a bela-arte pode ser dita bela e, portanto, não passível de conhecimento.

Por fim, não se pode esquecer que a bela-arte é uma arte e, como tal, pressupõe um criador. Mas uma obra tão peculiar quanto a bela-arte exigirá um produtor à sua altura. Se até agora nosso problema era entender a possibilidade do termo belo-arte, agora ele passa a ser o de entender a possibilidade de produção da bela-arte. A exemplo do parágrafo anterior, o parágrafo 46 já traz em seu título a solução do problema: Bela-arte é arte do gênio - onde gênio é assim definido: "Gênio é o talento (dom natural) que dá à arte a regra. Já que o talento, como faculdade produtiva inata do artista, pertence, ele mesmo, à natureza, poderíamos também exprimir-nos assim: gênio é a disposição inata (ingenium), pela qual a natureza dá à arte a regra” (Kant 2, p. 246).

Assim, o gênio é um privilegiado da natureza, um homem capaz de produzir bela-arte: "(...) belas-artes têm de ser necessariamente consideradas como artes do gênio" e a "(...) bela-arte só é possível como produto do gênio" (id., ibid.). Ele é um homem com o dom natural de dar à arte uma regra própria, dom esse que lhe é inato. É como se o gênio construísse uma outra natureza, um mundo próprio dentro das molduras de sua obra. Essa capacidade Kant chama de talento: "(...) é [o gênio] um talento, de produzir aquilo para o qual não se pode dar nenhuma regra determinada: não disposição de habilidade para aquilo que pode ser aprendido segundo alguma regra; conseqüentemente, que originalidade tem de ser sua primeira propriedade" (id., ibid.).

Sendo esse dom tão particular, não há como determiná-lo: nem mesmo o gênio pode saber, se entendermos por saber uma descrição do tipo científica, o que o faz gênio. O gênio em Kant não é o gênio matemático: “(...) a natureza pelo gênio, preescreve, não à ciência, mas à arte a regra; e também isto somente na medida em que esta última deve ser bela-arte" (id., ibid., p. 247).

O parágrafo 47 da Crítica do Juízo, tal como indica seu título, tem por objetivo elucidar as definições e considerações apresentadas anteriormente. Nele, Kant diz: "Nisto todos concordam: que gênio deve ser inteiramente oposto ao espírito de imitação. E, como aprender nada é senão imitar, a máxima ap- 
tidão, facilidade de assimilação (capacidade) como tal, não pode valer como gênio" (Kant 2, p. 247).

Há aqui algo que nos parece de extrema importância e que nos ajudará a pensar a originalidade (definida como a primeira propriedade do gênio): o gênio é oposto à imitação. Se voltarmos à noção de bela-arte e à maneira como ela é definida pelo parágrafo 45 , chegaremos à seguinte questão: a belaarte deve parecer natureza, ao mesmo tempo em que é obra de um sujeito que, por definição, não imita; ora, o que é então esse parecer natureza que não pode ser uma imitação da natureza?

Esse parecer natureza não pode ser uma cópia da mesma natureza. Para que uma arte seja objeto de um juízo de gosto ela não pode ser um retrato fiel da natureza: "Só que aqui confundimos, presumivelmente, nossa simpatia pela alegria de um pequeno animalzinho querido, com a beleza de seu canto, que (como ocorre às vezes com o trinado do rouxinol), se for imitado com toda precisão pelo homem parece ao nosso ouvido inteiramente sem gosto" (idem 3 , p. 240).

Uma longa passagem do parágrafo 48 é mais direta sobre o mesmo tema, explicitando o que fica implícito no trecho acima: "A bela-arte mostra sua preeminência justamente em descrever com beleza coisas que na natureza seriam feias ou desagradáveis. As fúrias, as doenças, devastações de guerra, e assim por diante, podem, como calamidades, ser descritas com muita beleza e até mesmo representadas na pintura; somente uma espécie de feiúra não pode ser representada conforme a natureza sem arruinar toda satisfação estética e, portanto, a beleza artística: a saber, aquela que desperta nojo. Pois, porque nessa singular sensação, que repousa sobre pura imaginação, o objeto é representado, por assim dizer, como se impusesse à fruição, contra a qual no entanto lutamos com violência; assim a representação artística do objeto não se distingue mais da natureza desse próprio objeto em nossa sensação, e então é impossível que aquele seja tido como belo. Também a escultura, porque em seus produtos a arte é quase confundida com a natureza, exclui de suas figurações a representação imediata de objetos feios e, em vez disso, permite representar, por exemplo, a morte (em um belo gênio), o ânimo guerreiro (em Marte), por uma alegoria ou atributos que resultem agradáveis, portanto apenas indiretamente, por intermédio de uma interpretação da razão, e não meramente para o Juízo estético" (idem 2, p. 250; grifo nosso). 
O que esse longo trecho parece ter em comum com o trecho da Analítica do belo, citado anteriormente, é a distinção entre bela-arte e a imitação precisa da natureza. Porém, a passagem do parágrafo 48 é mais explícita, pois por ela podemos entender que aquilo que torna a bela-arte bela não é, necessariamente, o que é belo na natureza. Uma guerra, que é terrível do ponto de vista da natureza, pode ser bela quando artisticamente representada. Mais do que isso, para que uma obra, um fazer humano, seja belo, ele não pode ser um retrato fiel da natureza.

É interessante notar o exemplo do nojo dado por Kant no parágrafo 48 da Crítica do Juízo. A representação artística do nojo jamais será bela, pois ela sempre será tão nojenta quanto o próprio nojo. Não há assim diferença, do ponto de vista de nossa sensação, entre o belo natural e sua representação artística, logo não pode ser uma beleza artística. Dessa maneira, se o efeito de algo representado em uma obra for o mesmo que na natureza, então não há aí beleza alguma.

A beleza artística presente na bela-arte deve-se justamente a essa diferença em relação ao que é belo na natureza; a obra de gênio, como vimos, não pode ser um mero retrato, cópia, da natureza. Logo, a imitação servil da natureza não pode ser objeto do gosto. Para que uma obra humana seja julgada pelo gosto, como faculdade que o julga o belo, ela tem de ser muito mais que uma mera cópia da natureza: ela tem de ser algo como um ideal de natureza. No caso do gênio em Kant poderíamos ver esse ideal como uma maneira particular de combinar elementos e expô-los de uma tal forma que suscite o sentimento de prazer de quem o contempla. Tanto essa maneira de trabalhar elementos dados, quanto a forma encontrada para expô-los, caracterizam a originalidade do artista.

A bela-arte então pode parecer natureza, pois o gênio sabe, pelo seu dom natural, a medida certa de trabalhar - produzir sua obra. Parecer natureza é algo distinto de imitar a natureza e o gênio é único capaz de produzir algo que pareça, para aquele que julga, natureza. Ele surge assim como alguém absolutamente original que encontra em seu dom de nascença o meio de suscitar o prazer dos outros. Com seu talento natural, o gênio acaba por unir dois elementos opostos (arte e natureza) possibilitando o termo bela-arte.

Como obra de gênio, a bela-arte é o que Kant chama de Idéia estética, ou seja: “(...) aquela representação da imaginação, que dá muito a pensar, sem que entretanto nenhum pensamento determinado, isto é, conceito, possa ser- 
lhe adequado, que consequentemente nenhuma linguagem alcança totalmente e pode tonar inteligível" (Kant 2, p. 251).

Muito embora todas as pessoas tenham imaginação e entendimento, a maneira como essas faculdades atuam no gênio é tão particular e original quanto sua obra. Nele, enquanto a imaginação, por assim dizer, libera suas asas em um grande vôo, o entendimento consegue dar a esse vôo um pouco de determinação capaz de torná-lo comunicável. O resultado não é um conceito determinado, mas uma Idéia estética: é, por fim, a bela-arte. Se, por um lado, o gênio é caracterizado por uma imaginação capaz de vôos incríveis, por outro, há a necessidade de um entendimento capaz de transformar esse vôo em algum tipo de linguagem a ser apreciada pelo admirador de sua obra.

Da mesma forma que o gênio não imita, ele não pode ser imitado naquilo que o faz gênio. Sendo original, sua capacidade de criar não pode ser copiada. Um quadro de gênio, ou um estilo de um determinado gênio até podem ser imitados, mas a originalidade que os torna belos e que neles foi, de certa forma, imprimida pelas mãos do gênio, jamais será copiada. O máximo que uma obra de gênio pode fazer, nesse sentido, é despertar a genialidade de um outro gênio ao contemplá-la, mas para tanto seria preciso que esse que está se descobrindo gênio já tivesse em si o talento natural da genialidade. Nada faz um gênio senão a ocasião de ter nascido gênio.

No início do parágrafo 48, Kant diz: "Para o julgamento de belos objetos, como tais, é requerido gosto; para a bela-arte, porém, isto é, a produção de tais objetos, é requerido gênio" (id., ibid., p. 249).

Kant marca a diferença entre o espectador e o produtor da bela-arte. Todos podem ter gosto, uma vez que todos têm imaginação e entendimento; $o$ sentimento de prazer e desprazer é universalmente comunicável. Assim, a bela-arte, como objeto de um juízo de gosto, deve ser universalmente contemplada ou antes ter essa pretensão. A obra de gênio pode ser universalmente admirada na medida em que pretende suscitar o prazer daqueles que por ventura venham lhe contemplar. Mas nem todos possuem esse dom natural de produzir algo que será julgado como belo. O parágrafo 50 da Crítica do Juízo, termina com os seguintes requisitos para a produção da bela-arte: "Para belaarte, pois, seriam requisitos imaginação, entendimento, espírito e gosto" (id., ibid., p. 256). 
O parágrafo anterior havia definido espírito da seguite maneira: "Espírito, no sentido estético, significa o princípio vivificador da mente. (...) Ora, eu afirmo que esse princípio não é outro do que a faculdade de exposição de Idéias estéticas" (Kant 2, p. 251).

O gênio, como homem de espírito e que é capaz de imprimir espírito em sua produção, parece estar intimamente ligado à idéia de expor uma obra que deve ser julgada como se fosse natureza . Dessa forma, ele ganha seu estatuto de gênio ao expor uma bela-arte, ou seja: na ocasião em que suscita o prazer de seu público. O talento do gênio em Kant, assim como a originalidade que deve ser sua primeira propriedade, vêm sempre acompanhados da produção e da exposição de sua obra: a bela-arte. O próprio termo arte pressupõe um fazer que já é estar expondo a obra. Embora não seja um simples artesão (Handwerker), o gênio não é nada sem a técnica que o faz artista. Nesse sentido, ele pode ser entendido como a boa medida entre o espírito e as mãos: ele seria, ao mesmo tempo, Handwerker e Geisteswerker.

Assim, se retornarmos ao nosso amargurado Mestre Romão, a partir de um ponto de vista de kantiano, veremos que ele, como vocação sem língua, tem toda razão em ser triste. No lugar de despertar o sentimento de prazer dos outros, mestre Romão teve a infelicidade de ter de conviver com o seu próprio desprazer.

Abstract: The main goal is to enquiry the relationship between the notions of Darstellung and Genius as they appear in Kant's Critique of Judgement.

Key-words: exposition - genius - fine art 


\section{Notas}

1. Mantivemos a grafia original das palavras, tal como empregada por Machado de Assis. 2.Em Dogamtismo e anti-dogmatismo: Kant na sala de aula (Torres 5), Rubens Rodrigues Torres mostra como a preposição alemã als aparece como signo de uma maneira de pensar que prima por estabelecer um ponto de vista a partir do qual se pensa algo inserido no seu local adequado. Não é à toa, como nota Torres, que Kant emprega tantas palavras para designar "lugar", "espaço adequado" (ele utiliza Ort, Platz, Stelle) - trata-se de encontrar a maneira correta de representar algo, o ponto de vista a partir do qual julgamos um objeto. Assim, por exemplo, podemos julgar a natureza como se (als ob) fosse arte, e a arte como se ( $a l s o b)$ fosse natureza. No primeiro caso vemos a natureza sendo julgada sob o ponto de vista do juízo teleológico e, no segundo, a arte sendo julgada sob o ponto de vista do juízo de gosto.

3. Ao contrário do prazer interessado, o prazer suscitado pelo belo é um prazer puro: "Tem [o prazer puro], no entanto, causalidade em si, a saber, para conservar o estado da própria representação e a ocupação dos poderes-de-conhecimento, sem outro propósito" (Kant 3, p. 224).

\section{Referências Bibliográficas}

1. ASSIS, J. M. M. "Cantiga de esponsais". Em: Histórias sem datas. Civilização Brasileira, Rio de Janeiro, 1975.

2. KANT, I. "Da arte e do gênio". Em: Os pensadores. Tradução de Rubens Rodrigues Torres Filho. Abril, São Paulo, 1980.

3. __ “Analítica do belo". Em: Os pensadores. Tradução de Rubens Rodrigues Torres Filho. Abril, São Paulo, 1980.

4. LEBRUN, G. Kant e o fim da metafísica. Tradução de Carlos Alberto Ribeiro de Moura. Martins Fontes, São Paulo, 1993.

5. TORRES FILHO, R. R. "Dogmatismo e anti-dogmatismo: Kant na sala de aula”. Em: Revista Tempo Brasileiro, Rio de Janeiro, n. 91, 1987. 